\title{
La concepción deliberativa de la democracia en la Jurisprudencia del Tribunal Constitucional Peruano
}

\section{The deliberative conception of democracy in the case- law of the Peruvian Constitutional Tribunal}

\author{
Alfonso Renato Vargas Murillo \\ Máster en Gobernanza Global y Derechos Humanos \\ Universidad de Castilla-La Mancha, Toledo - España \\ Correo electrónico: avargasmu@unsa.edu.pe

\begin{abstract}
Ilda Nadia Monica de la Asuncion Pari Bedoya
Maestranda en Cuestiones Contemporáneas en Derechos Humanos

Universidad Pablo de Olavide, Sevilla - España.

Correo electrónico: iparib@unsa.edu.pe
\end{abstract}

\section{Resumen}

El presente artículo tiene como objetivo explorar la concepción deliberativa de la democracia al interior del Tribunal Constitucional peruano. Por esto analizaremos los fallos emitidos por dicha corte, principalmente aquellos que aplican el control de constitucionalidad a los procesos legislativos por vicios en los procesos de deliberación, para identificar de qué manera se han incorporado las principales categorías derivadas de la democracia deliberativa en la fundamentación de su jurisprudencia.

\section{Palabras clave:}

Democracia, deliberación, Tribunal Constitucional, Perú, jueces. 


\section{Abstract}

The present paper aims to explore the deliberative conception of democracy within the Peruvian Constitutional Tribunal. For this reason, we will analyze the rulings issued by the aforementioned court, chiefly those that apply the constitutional review to legislative procedures due to flaws in the deliberation process, to identify in which manner the main categories derived from deliberative democracy have been incorporated in the elaboration of its case-law.

\section{Key Words}

Democracy; deliberation; Constitutional Tribunal; Peru; judges.

\section{Introducción}

Se ha reconocido la década de los ochenta del siglo XX, como el periodo de "gestación" del modelo de democracia deliberativa, con la aparición de trabajos como el de Joseph Besette Deliberative Democracy: The Majority Principle in Republican Government (1980), donde se acuña el término o el célebre trabajo de Jürgen Habermas “Teoría de la Acción Comunicativa” (1981), para establecer las bases filosóficas de esta concepción de la democracia. La década de los noventa, fue la época de “desarrollo y consolidación”, donde se produjo una amplia discusión en los medios académicos, hasta que a fines del siglo autores como James Bohmann -con la publicación de The Coming of Age of Deliberative Democracy (1998)- advierten la necesidad de pasar a un segundo nivel: plantear diseños institucionales, mecanismos de implementación y evaluación de la democracia deliberativa. De ahí que, desde inicios de siglo, la atención se haya centrado en las implicaciones prácticas del modelo (Martí, 2006). Este proceso de formación, desarrollo y consolidación se dio en un contexto de crisis generalizada de los sistemas políticos, que se vio reflejado en el desencanto ciudadano, la insatisfacción de los mecanismos de toma de decisiones y procesos de transición política en diversas regiones del mundo (Cuervo et al., 2012).

\footnotetext{
Cómo citar este artículo:

Vargas, A. R., \& Pari Bedoya, I. N. (2020). La Concepción Deliberativa de la Democracia en la Jurisprudencia del Tribunal Constitucional Peruano. Revista de la Facultad de Derecho y Ciencias Políticas, 50 (132), pp. 149-169. doi: http://dx.doi.org/10.18566/rfdcp.v50n132.a07

Recibido: 13 de junio de 2019.

Aprobado: 11 de septiembre de 2019.
} 
Sin embargo, la democracia deliberativa no es una corriente del todo homogénea, por lo que las diversas teorías de la democracia que se reconocen a sí mismas como pertenecientes a la corriente "deliberativista" se pueden clasificar de dos maneras: 1) la primera se refiere a los sujetos, la forma, el espacio o alcance del proceso deliberativo (participativas 0 representativas, reales o hipotéticas, nacionales o internacionales). 2) La segunda corriente parte de la concepción filosófica de la libertad política que sostiene su teoría (liberales, republicanas o críticas) (Olivares, 2018). Pese a esto, es posible reconocer a primera vista en cualquier concepto de democracia deliberativa dos elementos mínimos: el elemento democrático y el elemento deliberativo. El primero se refiere a la participación de manera directa 0 a través de representantes de los ciudadanos. El segundo, la deliberación, se entiende como un proceso comunicativo colectivo para la toma de decisiones (Martí, 2006).

Para resultar acorde a los propósitos de la democracia deliberativa, este proceso discursivo para la toma de decisiones puede evaluarse por la garantía de cinco condiciones: 1) Información, es decir, que los participantes tenn acceso a información que sea razonablemente precisa y relevante para la cuestión ${ }^{1}$. 2) Equilibrio sustantivo, esto es, que los argumentos ofrecidos por una de las partes hayan sido respondidos por los de aquellos que tienen otras perspectivas. 3) Diversidad, a saber, que las principales posiciones en el público deben estar representadas por los participantes de la discusión. 4) Concientización, se trata de que los participantes "pesan" sinceramente los méritos de los argumentos. 5) Igual consideración, es decir, que los argumentos ofrecidos por todos los participantes sean considerados por el "fondo" independientemente de cualquier ofrecimiento (Fishkin, 2009).

La recepción de los planteamientos de los teóricos de la democracia deliberativa por académicos peruanos se produce tempranamente, como se observa de los trabajos del filósofo peruano David Sobrevilla, quien en 1987 publicó el artículo titulado: "El programa de fundamentación de una ética

1 Cuando nos referimos a la "cuestión" aludimos, al objeto de la deliberación. Es decir, qué materias deben ser objeto del procedimiento de discusión pública en los términos de la democracia deliberativa. Al respecto, si bien no hay consenso, algunos autores sostienen que estas discusiones deben versar sobre cuestiones de moral pública o intersubjetiva, no involucrándose en cuestiones de moral privada (Giuffré, 2018). Esto resulta razonable en tanto la democracia deliberativa, si bien es un modelo que basa su legitimidad en criterios procedimentales principalmente, dicho procedimiento solo será posible en tanto se respeten los derechos (fundamentalmente el de igualdad y libertad) de las personas potencialmente afectadas por la decisión, por lo que la intervención sobre cuestiones relativas a la moral privada puede vulnerar tales derechos. 
discursiva de Jürgen Habermas” (1987). En 1990, otro filósofo peruano Miguel Giusti publicó el artículo "La ética discursiva de Jürgen Habermas” (1990)².

Pese a que el contexto de recepción de dichas ideas en los inicios de la década de los noventa se caracterizó por una situación de violencia política generalizada, un auto-golpe de Estado y la producción de una nueva Constitución Política (Constitución Política del Perú, 1993), cuya legitimidad democrática ha sido cuestionada (que dió origen a la célebre sentencia recaída en el Exp. N. ${ }^{\circ}$ 0142003-AI/TC); el panorama actual respecto de las posibilidades para consolidar una política deliberativa en las instituciones estatales en el Perú no resulta desfavorable. Esto es posible afirmarlo con Garrido-Vergara, Valderrama y Peñafiel (2016), en tanto podemos identificar una mayor cantidad de mecanismos de participación ciudadana, que pueden calificarse como "deliberativos" en mayor proporción a los de algunos países de la región, aun cuando el uso de estos mecanismos por la ciudadanía ha sido bajo ${ }^{3}$.

Para determinar en qué estado se encuentra la recepción de la democracia deliberativa como ideal regulativo de las prácticas políticas en las diversas instituciones estatales, resulta necesario analizar la manera en la que interactúan entre ellas y con la sociedad civil. En este sentido, sobre el caso peruano, los últimos años han surgido trabajos como los de Koechlin (2017) y Arenas (2017), donde se analiza la participación ciudadana en los presupuestos participativos de Cusco, Lima y Puno. También encontramos el trabajo de Irigoyen y Chávez (2017) sobre la experiencia en torno al Grupo de Diálogo, Minería y Desarrollo Sostenible (GDMDS) como experiencia exitosa de prácticas dialógicas para solución de conflictos medioambientales. Asimismo, el trabajo de Paredes (2017), que aborda desde una perspectiva filosófica la situación de la democracia en el Perú y conecta procesos como el de consulta previa con el ideal democrático deliberativo.

Una de las instituciones que ha ganado mayor atención en la academia peruana, por su relación con el ideal de democracia deliberativa, ha sido el

2 Artículo que fue resultado de su ponencia en el marco de un coloquio organizado por el Instituto Goethe en Lima sobre la obra de Habermas con motivo de la visita del filósofo alemán al Perú (Giusti, 1990).

3 Un caso particular es el de los países que han sido agrupados alrededor de la etiqueta de "Nuevo Constitucionalismo Latinoamericano" (Bolivia, Ecuador y Venezuela). Como señala Quiroz-Villalobos (2019), estos países frente a la crisis de los noventa vieron un incremento en la participación ciudadana que dio como resultado a Cartas Políticas con mecanismos de participación que prometen profundizar la democracia; pero que al haberse producido en el marco de "presidencialismos fuertes" se ha obstaculizado la obtención de tales objetivos. 
Tribunal Constitucional peruano. Sosa-Sacio (2017) y Rojas-Bernal (2017) identifican las sentencias estructurales como expresiones de un activismo judicial de tipo "dialógico", concordante con el ideal de democracia deliberativa, en tanto mantiene interacciones entre el Tribunal Constitucional, la sociedad civil y los órganos estatales al declarar un estado de cosas inconstitucional. Otros trabajos como el Ku-Yanasupo (2017) y Cruces (2018) han estudiado la declaración de inconstitucionalidad de los vicios deliberativos del procedimiento legislativo y su relación con la democracia deliberativa.

A través de estos trabajos podemos percibir que existe una "inclinación" de los magistrados por las "salidas dialógicas", con respecto a diversas causas que han sido llevadas ante su tribunal. Por lo que, antes de poder hablar de una "línea jurisprudencial” de la democracia deliberativa (Durango, Marín y Valencia, 2017) desarrollada por dicha corte, resulta necesario analizar, a través del discurso judicial, de qué manera se han incorporado las principales categorías de la democracia deliberativa en la fundamentación de sus sentencias.

\section{Cortes constitucionales y democracia deliberativa}

Mendes (2018) señala que es posible identificar cinco imágenes, no excluyentes entre sí, de las Cortes constitucionales, a través de los debates que se producen en torno a sus funciones y el lugar que ocupan en nuestra sociedad:1) imagen de guardiana, 2) órgano con poder de veto, 3) la razonadora pública, 4) interlocutora e 5) imagen de deliberadora. Para la democracia deliberativa resultan especialmente relevantes las tres últimas imágenes, ya que se refieren, por un lado, a la actuación de las cortes en el espacio público y a la manera en la que interactúan con otros actores. Por el otro, a la forma en la que se relacionan "argumentativamente" los jueces que conforman dicho colegiado para proferir sus sentencias.

Los problemas del sistema político que se manifiestan, por ejemplo, en el favorecimiento indebido a ciertos grupos que tienen la capacidad de ejercer presión sobre los órganos de toma de decisiones. En este contexto, las críticas desde la democracia deliberativa se enfocarían en los siguientes aspectos: dichas decisiones restringen o debilitan la deliberación, son resultado de un procedimiento viciado y están basadas en una deliberación imperfecta, en tanto no se consideraron argumentos relevantes o las conclusiones no han sido justificadas públicamente. Desde esta perspectiva, los jueces estarían en una posición propicia para promover la corrección tales deficiencias en términos 
deliberativos, cuando sean requeridos por aquellas personas afectadas por dichas decisiones y, por tanto, estén obligados a escuchar a ambas partes del conflicto, al analizar en dicho proceso las debilidades del sistema político. Asimismo, ellos cuentan con mecanismos para realizar esa labor y actuar de manera respetuosa con los otros poderes (Gargarella, 2006).

Situaciones como las descritas, han propiciado que desde los años 90 , autores como Habermas o John Rawls hayan teorizado respecto a la posibilidad de que instituciones como la de control judicial de constitucionalidad permitan realizar los fines de la democracia deliberativa (Olivares, 2017). No obstante, los primeros trabajos elaborados por teóricos de la democracia deliberativa referidos al rol del derecho y los jueces tuvieron un alto grado de generalidad, al pasar por alto varias cuestiones relativas al diseño institucional de las cortes (Giuffré, 2018).

La evolución de las prácticas de los tribunales en diversas partes del mundo como Colombia, India, Sudáfrica o Canadá relativa a la tutela de los Derechos Económicos, Sociales y Culturales ha dado origen al denominado "constitucionalismo dialógico". Podemos definir el constitucionalismo dialógico como una corriente constitucional basada en la idea de que los órganos estatales deben promover mecanismos que permitan la participación ciudadana, a través de procedimientos dialógicos e incluyentes en el proceso de toma de decisiones en el marco de sus atribuciones constitucionalmente establecidas (Córdova, 2016).

Es así que, en el caso del surgimiento de esta corriente constitucional que tiene como origen los planteamientos de la democracia deliberativa, la relación entre teoría y práctica resulta bastante compleja, dado que el constitucionalismo dialógico, en tanto modelo de constitucionalismo, se encuentra en un constante proceso de "refinamiento" (Giuffré, 2018, p. 46) por constituirse a partir de las prácticas reales de las cortes.

El carácter dialógico de este modelo de constitucionalismo según Giuffré (2018) se distingue por: 1) la igualdad de los participantes en el momento de intervenir e incidir en la discusión. 2) Inclusión social, esto es, la oportunidad de que todos los potencialmente afectados puedan intervenir en el proceso deliberativo; especialmente aquellos que tienen dificultades para la intervención. 3) La deliberación argumentativa, el intercambio de razones y la posibilidad de ceder ante el mejor argumento. 4) La continuidad del proceso, por lo que se debe estimular la deliberación. 5) La publicidad del proceso, la 
transparencia de las razones que motivan las decisiones y que puedan conocerse oportunamente por los interesados. 6) La libertad de los participantes para decidir sobre la oportunidad y el contenido de la discusión, siempre y cuando verse sobre cuestiones de moral intersubjetiva. 7) La orientación del discurso al consenso, resultando deseable que el debate finalice con un acuerdo con respecto al triunfo del mejor argumento. 8) La promoción institucional del diálogo y la existencia de reglas predeterminadas para que se promueva la deliberación con la finalidad de evitar su instrumentalización y manipulación. 9) La orientación del discurso a la sociedad y la búsqueda de "horizontalidad" en el diseño de los procesos de diálogo.

En resumen, para los fines de la democracia deliberativa, las Cortes constitucionales deben actuar como articuladores del diálogo, al garantizar la participación de los diversos actores que intervienen en el espacio público en condiciones de igualdad. Así, el diálogo no se agota en el debate intrainstitucional que se produce entre los jueces en el momento previo de la toma de decisiones; sino que se debe posibilita, a través de diversos mecanismos (como las audiencias públicas, la participación de amicus curiae y terceros), que los presuntamente afectados por la medida que se va a adoptar puedan exponer sus razones e interactuar entre sí. Del mismo modo, en el momento de realizar el seguimiento a la implementación de las sentencias, la corte debe actuar como "coordinador" entre las instituciones públicas y la sociedad civil.

Sin embargo, como anotamos al inicio, al no existir una definición unívoca de democracia deliberativa y ante la evolución del modelo resulta necesario identificar los rasgos característicos de la concepción deliberativa de la democracia que desarrolla la corte bajo estudio, a fin de comprender mejor dichas prácticas.

\section{La democracia deliberativa según el Tribunal Constitucional peruano}

Si bien es posible identificar prácticas correspondientes a un "incipiente constitucionalismo dialógico” por parte del Tribunal Constitucional peruano en las sentencias estructurales y la tutela de derechos sociales (Rojas-Bernal, 2017; Sosa-Sacio, 2017), el "giro dialógico" o "giro deliberativo" se puede observar con mayor claridad a partir de las reflexiones respecto a la relación 
entre legitimidad democrática y deliberación de las sentencias del tribunal a partir del año 2016 sobre los procesos de control de constitucionalidad sobre los "vicios deliberativos" de los procesos legislativos.

\subsection{La deliberación democrática como fundamento de legitimidad de las prácticas legislativas}

Para poder ilustrar el proceso de evolución del concepto de deliberación al interior del Tribunal Constitucional es necesario referirnos a sentencias previas al denominado "giro deliberativo" propiamente dicho. La Corte expresó que, la legitimidad de las decisiones emitidas por el Congreso de la República se funda en la voluntad política de las mayorías. Por ende, estas descansan en su relación con el cuerpo electoral; sin perjuicio de que estas deban cumplir con los criterios de racionalidad y deliberación (Sentencia Exp. No 0005-2011-PI/ TC de 2011, fund. 9).

El cambio se observa si comparamos lo advertido en la sentencia anterior con la dicho por el Tribunal Constitucional en una sentencia posterior donde señalaron que, si bien las limitaciones de derechos se justifican, en primer lugar, en cuanto sean incorporadas mediante una fuente formal del derecho, su legitimidad descansa en

las prácticas y principios democráticos que subyacen en el proceso previo a su sanción y promulgación. En concreto, asegurar que la limitación a los derechos haya sido objeto de una deliberación pública y plural y que cuente con la aquiescencia de los representantes de la sociedad en el Estado (Sentencia Exp. Nº010-2014-PI/TC de 2016, fund. 34).

Así, para la corte el control de constitucionalidad realizado sobre el proceso legislativo se justifica a partir de la idea de "interdicción de la arbitrariedad", entendida como el deber de ponderación frente a las restricciones de derechos, que se extiende (conforme el Estado Constitucional de Derecho) hasta los legisladores (Ku-Yanasupo, 2017). De esta manera, se empieza a observar los primeros rasgos derivados de una concepción deliberativa de la democracia: la legitimidad de las decisiones políticas, especialmente aquellas que implican una limitación de derechos, deben ser justificadas a través de un procedimiento dialógico, que si bien no son los claros los límites de 
la "publicidad" y "pluralidad" mencionadas, se puede comprender como la apuesta por procesos menos restrictivos, más abiertos e incluyentes.

La primera referencia expresa sobre la concepción deliberativa de la democracia se produce en un Voto Singular del magistrado EspinozaSaldaña. En este caso el magistrado critica los modelos "mayoritaristas" de legitimidad democrática, como el sostenido en el Exp. N 0005-2011-PI/TC. Es por esto que señala que los vicios en la deliberación de los procedimientos legislativos,además de ser vicios formales, constituyen: "graves infracciones que lesionan el principio democrático consagrado en la Constitución” (Sentencia Exp. N 00015-2012-PI/TC de 2017, fund. 2).

Para el magistrado, constituyen déficits deliberativos la carencia de argumentación, espacios de discusión y revisión de las decisiones, al dejar en claro que el modelo de legitimidad democrática adoptado, en tanto exigencia del Estado Constitucional de Derecho contemporáneo, es aquel en el que "la legitimidad de las decisiones públicas se basan en las razones ofrecidas a su favor, y no en la imposición arbitraria del poder, por lo cual bien puede hablarse de un giro argumentativo o deliberativo en la concepción de la democracia” (Sentencia Exp. № 00015-2012-PI/TC de 2017, fund. 2). Es así como esta sentencia puede inaugurar el giro deliberativo "propiamente dicho" de la concepción de la democracia dentro del Tribunal Constitucional.

Al respecto, es posible comprender la posición del magistrado sobre a la naturaleza del control de constitucionalidad de los vicios deliberativos en los procedimientos legislativos. Según Ku-Yanasupo (2017), como la defensa de un modelo "semiprocedimental", que no es ni puramente sustantivo o procesal, en tanto se discute y se decide; mientras que la labor legislativa implica mucho más que el cumplimiento de las pautas procedimentales establecidas en la Constitución. Por consiguiente, desde esta perspectiva el control de constitucionalidad "puramente" sustantivo solo debería aplicarse donde se produzca de manera flagrante una violación sustantiva a la Constitución. Este modelo semiprocedimental permite que los órganos legislativos puedan volver a promulgar la norma invalidadas, siempre que haya seguido el proceso legislativo establecido en la Constitución.

Este mecanismo de judicial review, resulta bastante conveniente para los fines de la democracia deliberativa, pues al centrar su atención en la legitimidad democrática de las decisiones políticas, este mecanismo permitiría un "reenvío" toda vez que la declaración de inconstitucionalidad del modelo 
semiprocedimental no excluya la posibilidad de que los órganos legislativos puedan volver a emitir la norma declarada inconstitucional, una vez subsanada los vicios deliberativos. Por tanto, como han sostenido Durango, Marín y Valencia (2017) y García-Jaramillo (2016), el poder judicial se convierte en promotor de la deliberación pública. Situación que no hace más que reforzar la idea de que, a partir de las prácticas de Cortes constitucionales como la colombiana, se hace cada vez más estrecha la relación entre los procesos de inconstitucionalidad por vicios parlamentarios y la democracia deliberativa.

El Tribunal Constitucional, si bien se retoma lo advertido en las sentencias anteriores con respecto a que los déficits de deliberación, estos no deben considerarse como meros "vicios formales" (Sentencial Exp. No 0017-2012PI/TC de 2018, fund. 12). Es preciso que los déficits de deliberación y reflexión puedan presentarse también en normas elaboradas a nivel subnacional. Por lo que la democracia deliberativa en su dimensión institucional (Guerra, 2015) no debe agotarse en las instituciones políticas de carácter nacional, comprendiendo a los municipios y gobiernos regionales, en tanto ejercen funciones de carácter legislativo.

El Tribunal Constitucional advierte que, si bien se ha establecido como forma de gobierno la separación de poderes (Constitución Política del Perú, 1993, art. $43^{\circ}$ ), esta comprende entre sus rasgos característicos el principio de "solución democrática". El TC señala que este principio se refiere a que frente a conflictos derivados de algún "entrampamiento" o "crisis política”, que no puedan ser superados por los medios institucionales habituales, se debe preferir el diálogo institucional o "a través de los espacios de deliberación pertinentes y adecuados para enfrentar los conflictos políticos” (Sentencia Exp. $N^{\circ}$ 0006-2018-P1/TC de 2018, fund. 56).

A primera vista, el modelo de separación de poderes no presenta problema o dificultad alguna para poder cumplir los fines de la democracia deliberativa - como han advertido los partidarios de un modelo constitucional deliberativo o dialógico como Conrado Mendes o Roberto Gargarella - , siempre y cuando el modelo de la teoría de los frenos y contrapesos, que responde a una lógica agonal de interacción entre poderes, sea desplazado del centro por una teoría dialógica y comunicativa de la división de poderes (Olivares, 2015). En este sentido, como ha advertido la corte, la separación de poderes incluye no solo el principio de checks and balances; sino el de cooperación y coordinación de poderes, por lo que la tensión que puede producirse entre ambos modelos al responder a lógicas distintas de interacción de poderes, solo puede resolverse 
en tanto los órganos políticos y jurídico-políticos adopten en la práctica y se comprometan con la solución dialógica (Sentencia Exp. № 0006-2018-P1/TC de 2018, fund. 47).

En el "Fundamento de voto de la Magistrada Ledesma Narváez", se señala que está de acuerdo con los fundamentos y la decisión del tribunal, en base a concebir una particular relación entre deliberación y democracia parlamentaria en el Estado Constitucional de Derecho:

En un Estado Constitucional, las leyes deben ser elaboradas con una suficiente, aunque mínima deliberación. Pero no sólo deliberación en el Pleno del Parlamento, en una sola votación, sino deliberación entre congresistas en las comisiones especializadas con la ayuda de especialistas y representantes de los diferentes sectores que serán materia de regulación. Si las leyes van a desarrollar y limitar los derechos fundamentales de las personas y por su alcance general van a regular amplios ámbitos de la sociedad, tienen que ser sustentadas en el más extenso nivel deliberativo (Sentencia Exp. N Exp. 0006-2018-PI/TC de 2018).

La magistrada recurre a una cita de la obra del teórico de la democracia deliberativa Jürgen Habermas denominada "Facticidad y validez" (1998) donde señala que:

el desarrollo y consolidación de una práctica deliberativa, la teoría del discurso los hace depender, no de una ciudadanía colectivamente capaz de acción, sino de la institucionalización de los correspondientes procedimientos y presupuestos comunicativos, así como de la interacción de deliberaciones institucionalizadas con opiniones públicas desarrolladas informalmente (Habermas, 1998, p. 374).

En primer lugar, la magistrada apela a la extensión en términos de participación deliberativa en el proceso de elaboración legislativa, en tanto el resultado puede incidir en el estado de los derechos fundamentales o tener un alto impacto social. Pero este proceso no puede ser autorreferencial, pues si bien la institucionalización de la deliberación es una muestra de la consolidación de la democracia deliberativa, esto no quiere decir que se pierda la interacción dialógica entre los diversos actores que intervienen en el espacio público. 


\subsection{La discusión sobre los problemas centrales de la democracia deliberativa}

El Tribunal Constitucional ha desarrollado algunos de los tópicos comunes a cualquier concepción deliberativa de la democracia: el problema de los desacuerdos y el pluralismo, los espacios y mecanismos deliberativos, el problema de la certidumbre respecto a las decisiones desde la razón comunicativa, la búsqueda de consensos y la evaluación de la calidad deliberativa (Sentencia Exp. Nº0006-2017-PI/TC de 2017).

\subsubsection{Desacuerdos y pluralismo}

Sobre al problema de los desacuerdos como problema fundamental de la interpretación constitucional contemporánea, el Tribunal Constitucional señaló:

3. La democracia representativa ${ }^{4}$, que se presenta en un contexto de pluralismo, contrasta con la noción del liberalismo decimonónico, el cual enfatiza la dimensión homogénea de las sociedades. Este pluralismo ideológico, social, cultural y económico, que es la suma de intereses particulares, debe ser traducido en planteamientos políticos y jurídicos que puedan reflejarse en actuaciones estatales, a fin de hacerlos compatibles con los valores constitucionales. Para ello, es necesario un proceso de deliberación que permita tomar en cuenta esta mixtura de ideas y su compatibilidad con la Constitución (Exp. № 00006-2017-PI de fecha 29 de agosto de 2017, fund. 3).

Esta pluralidad de ideas o concepciones ideológicas, sociales, culturales o económicas, lejos de ser un escollo para la democracia, los teóricos de la democracia deliberativa han hecho del desacuerdo moral su raison d'être. Es por esto que se presenta como una alternativa que, si bien puede que no termine por disolver dichos desacuerdos, puede llevar a una decisión que resulte aceptable por todos (Bohman, 2016).

4 Si bien pude pensarse a un inicio que la democracia deliberativa es una apuesta por la democracia directa en reemplazo del sistema representativo, García Alonso (2015, p. 60) aclara que: "La representación puede facilitar que la deliberación no tenga que estar condicionada por el tiempo, el espacio y la necesidad de tomar una decisión, que puede perjudicar la calidad de sus resultados. La separación en distintos momentos de la deliberación y la toma de decisiones, al contrario de lo que ocurre con la democracia directa, permitiría a los ciudadanos que la deliberación no estuviera condicionada por esos factores que pueden perjudicar la calidad de sus resultados". Por tanto, no existe incompatibilidad entre representación y democracia deliberativa. 
Conforme Waldron y Nino, al asumir el factum de la pluralidad y los desacuerdos ineludibles, la democracia deliberativa presenta a la deliberación y la participación como "los mejores procesos para acercarnos a decisiones imparciales" (Arrimada, 2011, p. 90). Asimismo, desde la perspectiva de Joshua Cohen (2007), la democracia deliberativa tiene dentro de sus rasgos principales el carácter de "asociación pluralista", esto implica que si bien tienen diversas convicciones, ideas o preferencias sobre la manera en la que conducen sus vidas, cuando se refieren a problemas elegidos para su discusión pública, al no asumir la existencia de una postura única obligatoria, se comprometen con una resolución deliberativa de los problemas. Esto se explica, toda vez que dichos miembros se reconocen mutuamente como capaces de participar en el intercambio público de razones y de actuar acorde al resultado de dicho procedimiento.

Un aspecto importante que no aparece en dicha sentencia y necesario para poder posibilitar una deliberación libre y plural en una sociedad democrática, como advierte el Tribunal Constitucional, para que exista una deliberación libre y plural en una sociedad democrática debe garantizarse la libertad de información (Sentencia Exp. Nº012-2018-PI/TC y 013-2018-PUTC de 2018, fund. 162). En un primer momento, la libertad de información permitirá a los participantes del discurso contar con mayores recursos argumentativos; así, ante la posibilidad de haber obtenido información errónea o escaza, a través de la discusión pública se intercambia información que permitirá corregir y neutralizar las desigualdades informativas (Martí, 2006).

\subsubsection{Espacios de deliberación y mecanismos deliberativos}

Sobre los espacios y mecanismos de deliberación, el Tribunal Constitucional ha desarrollado la idea del Congreso como espacio deliberativo por excelencia y advierte sobre confundir ciertas prácticas con la deliberación, como es el caso de la votación (sin deliberación previa o suficiente):

4. Uno de los espacios idóneos y predominantes para materializar dicho proceso de deliberación es el Congreso. En efecto, este es un auténtico órgano deliberante. Es el espacio donde se resuelven las tensiones y desacuerdos que surgen de la propia realidad plural que determina y enmarca las relaciones jurídicas y políticas. No obstante, el proceso deliberativo no debe ser confundido con las actividades que pretenden dar apariencia de deliberación. Y es que aquellos procesos en los que solo se enfatice el proceso de contabilizar votos distan mucho de ser procesos 
deliberativos. La cuantificación de votos ha de ser, en todo caso, el resultado de las deliberaciones, en donde sean las razones de peso las que precedan al conteo de votos, de manera que dicho elemento no sea el determinante, sino las razones que se encuentran detrás de los mismos. Esta clase de deliberaciones, y no los votos en sí, son los que brindan legitimidad a una decisión y a la entidad que las emite (Sentencia Exp. № 00006-2017-PI/TC de 2017, fund. 4).

La idea de parlamento como espacio donde se toma decisiones a partir de la deliberación democrática de los asuntos públicos, al no ser una idea "nueva”, puesto que en el siglo XVIII Burke calificaba al parlamento como una "asamblea deliberativa" y en The Federalist Papers se hablaba de una combinación entre deliberación y democracia (Gutmann y Thompson, 2001), nos deja la siguiente pregunta: ¿a qué tipo de deliberación se refiere?. La propuesta de la democracia deliberativa no promueve cualquier tipo de discusión; sino una de carácter inclusivo, donde los participantes tienen el derecho de participación garantizado por igual, en un proceso de carácter público y donde no intervenga coerción alguna (externa o interna). Esto tiene como finalidad que las decisiones sean resultado de la fuerza del mejor argumento produciendo un "acuerdo racionalmente motivado" (García-Alonso, 2015, p. 53).

Si partimos de la idea de que los parlamentos deben representar a la ciudadanía y, dado su carácter plural, la toma de decisiones sin la discusión pública resulta inadmisible, en tanto la democracia deliberativa contempla como presupuesto la imposibilidad de superar los desacuerdos existentes sino es a través de la búsqueda del (deseable) consenso por la exposición de las mejores razones. Así, a partir de la publicidad del procedimiento deliberativo, las razones que dieron sustento a la decisión, así como la decisión misma podrán ser evaluadas por aquellos que se consideren presuntamente afectados por la medida.

De existir el compromiso real con la deliberación democrática, como la fuente de legitimidad de una institución política, en este caso el parlamento, según Cohen (2007) es preferible que la conexión entre la deliberación y sus resultados sea lo más evidente posible. Por tanto consideramos que resulta importante la publicidad como rasgo fundamental del procedimiento legislativo, a fin de poder denunciar la toma de decisiones mediante "deliberaciones aparentes” o nula deliberación. Este parece ser un criterio compartido por el Tribunal Constitucional peruano. 
Para reforzar dicha tesis, el Tribunal Constitucional formula un discurso de corte histórico para justificar la adopción del modelo deliberativo de democracia como ideal que debe inspirar las prácticas políticas (en especial la parlamentaria). Para esto, la corte apeló a la figura de Pericles, afirmando que desde la antigüedad existió preferencia por "el intercambio informado como premisa para el perfeccionamiento del debate sobre las cuestiones de carácter público" (Sentencia Exp. Nº001-2018-PI/TC de 2018, fund. 23).

La figura de Pericles ha sido usada por teóricos de la democracia deliberativa para ilustrar el momento en la historia en el que las instituciones fueron reconocidas como particularmente democráticas y deliberativas. En el caso de la Atenas de Pericles fueron el Consejo (boulé), las Magistraturas y principalmente la Asamblea (Martí, 2006). Pericles defendió la idea de discusión pública como elemento esencial de la democracia, al sostener que los atenienses eran perfectamente capaces de juzgar cualquier idea o evento a pesar de sus ocupadas agendas derivadas de sus negocios o intereses personales (Osei, 2009). De esta manera, para Pericles — según lo escrito por el historiador ateniense Tucídides - la deliberación es el "preliminar indispensable de cualquier acción sabia” (citado por Gutmann y Thompson, 2001, p. 169).

En el fundamento del voto del magistrado Espinosa-Saldaña, señaló que el principio democrático (Constitución Política del Perú de 1993, arts. $3^{\circ}$ y 43) contiene un subprincipio denominado principio de deliberación, el cual implica "la discusión abierta e inclusiva de los asuntos públicos, la necesidad de ofrecer razones y espacios de deliberación o reflexión para la toma de decisiones, la existencia de mecanismos de fiscalización y control del poder, etc.)" (Sentencia Exp. N 0006-2018-PI/TC de 2018). Asimismo, dicha advirtió que la legitimidad de las decisiones políticas debe recaer en el "intercambio de razones públicas" y no solo en la voluntad de los legisladores. Esto al apelar a un proceso de “deliberación robusta” caracterizada por ser "plural, inclusiva, racional, y tendiente a acoger las mejores justificaciones, las cuales deben tener un carácter público” (Sentencia Exp. 0006-2018-PI/TC de 2018, fund. 18)..

El Tribunal Constitucional también ha resaltado la importancia del derecho a la participación política y la importancia de los procesos deliberativos. Así, señaló que el derecho a la participación política en democracia recae en la participación consciente de la ciudadanía en los procesos de deliberación pública, de manera individual u organizada (Sentencia Exp. N 0008-2018-PI/ TC de 2018, fund. 25). Por ejemplo, a través de los partidos políticos. 


\subsubsection{Certeza, verdad y calidad del proceso deliberativo}

Sobre el problema de alcanzar un contexto de certeza con respecto a la verdad de las premisas esbozadas en el proceso deliberativo, el Tribunal Constitucional advirtió lo siguiente:

5. Ahora bien, el proceso de deliberación sirve para el intercambio de información, así como colabora en la toma de decisiones. Sin embargo, ello no supone que mediante la deliberación se alcance necesariamente un contexto de certidumbre, pues en ocasiones las decisiones políticas son tomadas con diferentes grados de discrecionalidad. De este modo, la deliberación se erige como un proceso indispensable para poder enriquecer el debate no solo en cuanto a lo referido a la información que se pueda brindar, sino también en cuanto a perspectivas y enfoques. Y es que es la calidad del proceso deliberativo la que legitima la función legislativa, de ahí que se afirme que una norma jurídica se legitima como resultado de la deliberación general y no de la voluntad general (Sentencia Exp. ํㅜ 000062017-PI/TC de 2017, fund. 5).

El problema de la certidumbre (o incertidumbre) sobre lo que se decide en la democracia deliberativa, se expresa a través de uno de sus presupuestos normativos generales (es decir, comunes a cualquier concepción deliberativa de la democracia) como es la provisionalidad de las decisiones: "La deliberación es un proceso auto-correctivo, cuyos resultados son moralmente provisionales, atento están sometidos a continua revisión” (Olivares, 2013, p. 227). El carácter provisional de las decisiones derivadas del proceso deliberativo hace que éste sea concebido como un proceso abierto, en el sentido de que se mantiene siempre latente la posibilidad de reabrir los debates sobre el asunto que dio lugar a la decisión.

Para Gutmann y Thompsom (2004) las razones epistémicas que dan sustento a dicha afirmación son las siguientes: 1) la toma de decisiones tanto en la vida personal como en política, al depender del entendimiento humano no permite obtener certeza si aquello que decidimos hoy resulta correcto mañana o si a la luz de nuevas evidencias se vuelva menos justificable 2) Ante la dificultad de lograr consensos en política, las personas que no están de acuerdo con la decisión podrán acatarla con mayor facilidad si saben que existe la posibilidad de que en el futuro puedan presentar sus argumentos y revertir o modificar tal decisión. Por lo que el Tribunal Constitucional hace referencia a dos aspectos importantes de la propuesta deliberativa de la democracia: el 
compromiso asumido de los participantes de cambiar de opinión en el proceso de intercambio de razones y la existencia de un plazo razonable para que se produzca el proceso de intercambio de argumentos y luego se tome una decisión (Sentencia Exp. Nº001-2018-PI/TC de 2018, fund. 27).

Respecto de la calidad del proceso deliberativo debemos señalar que la democracia deliberativa al presentarse como un ideal regulativo, es decir al que debe tenderse en la medida de lo posible (Martí, 2006); resulta necesario para poder determinar el grado de adecuación de un proceso de toma de decisiones con el ideal democrático deliberativo pasar a un segundo nivel: el nivel evaluativo. Los teóricos de la democracia deliberativa han propuesto diversos criterios para evaluar la "calidad deliberativa", algunos de carácter normativo y otros empíricos (Greppi, 2012).

En consecuencia, del voto del magistrado Espinosa-Saldaña de la Sentencia se advierte que no basta con advertir los déficits deliberativos por el tribunal; sino que es su obligación establecer los criterios para poder evaluar dicha situación. El magistrado propone dos criterios: exigencia y suficiencia deliberativas (Sentencia Exp. Nº001-2018-PI/TC de 2018, fund. 38).

La exigencia se refiere a que existen algunos temas que por su importancia requieren mayores esfuerzos de los participantes en los debates y la búsqueda de consensos sobre las decisiones que se van a tomar. Estos temas son los relativos a los derechos humanos o aquellos esenciales respecto a la forma del Estado. El segundo, la suficiencia deliberativa se refiere a las condiciones mínimas de discusión y reflexión que se debe exigir a cualquier trámite de una resolución legislativa, dichos presupuestos son dos: 1) la deliberación mínima, entendida como la necesidad de que se intercambien razones respecto a las propuestas legislativas, lo que se produce en un primer momento en las comisiones (donde se permite la intervención de actores ajenos al parlamento) y el Pleno del Congreso. 2) La reflexión o revisión que implica evitar la arbitrariedad a partir de la reflexión respecto al contenido de la medida que se está tramitando, así como dar cuentas a los actores que se puedan ver involucrados respecto a aquello que se fuera a aprobar.

Es necesario precisar algunas cuestiones problemáticas en el primer criterio para evaluar la calidad deliberativa: La exigencia de una mayor y mejor deliberación con respecto a ciertos temas como los relativos a los derechos humanos podría inducir a error, en tanto se puede percibir como una barrera al proceso deliberativo. Sin embargo, para autores como Habermas 
(2001), derechos humanos y soberanía se encuentran en una posición de co-originalidad, es decir, ambos se requieren mutuamente y no pueden ser instrumentalizados como meros límites. En efecto, la existencia y vigencia de los derechos humanos permite la participación efectiva de los ciudadanos en los procesos deliberativos a través de sus representantes, lo que no implica que con ello se diluyan los desacuerdos sobre el contenido de dichos derechos. De lo contrario, lo que autores como Habermas sostienen es que no podría siquiera concebirse la discusión pública respecto de la interpretación de los derechos, sin que antes estén garantizados derechos como los de libertad de expresión, libertad de información, participación política, etc.

\section{Conclusiones}

El "giro deliberativo" en la jurisprudencia del Tribunal Constitucional peruano se produce cuando la corte al referirse a los fundamentos de la legitimidad de las decisiones políticas, en particular aquellas que limitan derechos, la deliberación deja de ser un elemento periférico o secundario (Exp. $\mathrm{N}^{\circ}$ 0005-2011-PI/TC) y ocupa el lugar central (Exp. Nº010-2014-PI/TC).

La deliberación como fundamento de la legitimidad democrática de las decisiones políticas según el Tribunal Constitucional se caracteriza por ser un proceso plural e inclusivo con respecto a los actores que participan en la discusión de los asuntos públicos. Esto implica que el debate no debe agotarse solo entre aquellos que tienen el poder de decisión. La decisión debe ser resultado de la reflexión para asegurar el triunfo de las mejores razones. Por último, deben existir mecanismos de revisión y control de los poderes públicos.

El Tribunal Constitucional peruano ha realizado un esfuerzo argumentativo a fin de demostrar la compatibilidad de la teoría de la democracia deliberativa y la Constitución Política del Perú, especialmente, en la configuración del Estado. Por consiguiente, según el Tribunal Constitucional peruano es posible identificar los fundamentos de una concepción deliberativa de la democracia en: a) la separación de poderes, en tanto comprende los principios de coordinación y cooperación interinstitucional, al señalar que debe preferirse el diálogo interinstitucional antes que la aplicación de mecanismos correspondientes a un modelo agonal de democracia como los frenos y contrapesos. b) El principio de deliberación, como sub principio del principio democrático, implica la garantía de que las decisiones sobre los asuntos públicos deben derivar de procedimientos dialógicos, abiertos e inclusivos, al garantizarse espacios 
para el ofrecimiento de razones y reflexión, así como mecanismos revisión y fiscalización de los poderes públicos.

\section{Referencias}

Arenas, M. (2017). Participación ciudadana en el presupuesto participativo de El Collao Ilave 2015 - 2016 (Tesis para optar el grado de licenciado en sociología, Universidad Nacional del Altiplano, Puno, Perú).

Arrimada, L. (2011). Sin frenos ni contrapesos: Democracia deliberativa: mucho más allá del presidencialismo y parlamentarismo. En L. García-Jaramillo (Coord.), La democracia deliberativa a debate. (pp. 75-96). Medellín: Universidad EAFIT.

Besette, J. (1980). Deliberative Democracy: The Majority Principle in Republican Government. En R. Goldwin y W. Shambra (Eds.), How Democratic is the Constitution?. (pp. 102-116). Washington (DC): American Enterprise Institute Press.

Bohman, J. (1998). The Coming of Age of Deliberative Democracy, Journal of Political Philosophy, 6 (4), pp. 400-425.

Bohman, J. (2016). La madurez de la democracia deliberativa, Revista Co-herencia, 13 (24), pp. 105-143.

Cohen, J. (2007). Deliberación y legitimidad democrática, Cuaderno Gris, III (9), pp. 127145.

Córdova, P. (2016), Constitucionalismo dialógico y última palabra. Una agenda de políticas deliberativas para las cortes constitucionales, Anuario de Derecho Constitucional Latinoamericano, XXII, pp. 253-270.

Cuervo, J., Hernández, A. y Ugarriza, J. (2012). El giro deliberativo en la democracia. Teoría y evidencia empírica. Bogotá: Universidad Externado de Colombia.

Durango, G., Marín, M. y Valencia, J. (2017). Línea jurisprudencial de la democracia deliberativa en la Corte Constitucional colombiana, Revista Estudios de Derecho, 74 (164), pp. 223-254.

Fishkin, J. (2009). When the people speak: Deliberative Democracy and Public Consultation. New York: Oxford University Press.

García Alonso, R. (2015). Representación política y democracia deliberativa. ¿Qué puede significar hoy la participación política?. Estudios Políticos, (47), pp. 47-66.

García Jaramillo, Leonardo. (2016). Construcción de una dogmática constitucional del procedimiento parlamentario: El caso colombiano, Revista de Derecho, XXIX (1), pp. 177-196.

Gargarella, R. (2006), ¿Democracia deliberativa y judicialización de los derechos sociales?, Perfiles Latinoamericanos, 28, pp. 9-32.

Giuffré, C. I. (2018). Democracia deliberativa y surgimiento del constitucionalismo dialógico, Revista Ética y Discurso, 1 (3), pp. 35 - 60.

Giusti, M. (1990). La ética discursiva de Jürgen Habermas. Areté: revista de filosofía, 2(2), pp. 171-186.

Greppi, A. (2012). La democracia y su contrario. Madrid: Trotta

Gutmann, A. y Thompsom, D. (2001). Deliberative democracy. En: P. Clarke y J. Foweraker (eds.), Encyclopedy of Democratic Thought (pp. 168-174). London: Routledge. 
Habermas, J. (1981). Teoría de la acción comunicativa, Tomos I y II. Madrid: Taurus. Habermas, J. (1998). Facticidad y Validez. Madrid: Trotta.

Habermas, J. (2001). Constitutional Democracy. A Paradoxical Union of Contradictory Principles?. Political Theory, 29 (6), pp. 766-781

Irigoyen, M. y Chávez, J. (2017). El Grupo de Diálogo, Minería y Desarrollo Sostenible (GDMDS) como experiencia democrática deliberativa en los procesos socioambientales del Perú, en el siglo XXI (Tesis para optar el grado de Magíster en Sociologia, Pontificia Universidad Católica del Perú, Lima, Perú).

Koechlin, J. G. (2017). Democracia y participación: análisis de los presupuestos participativos en el Perú. Los casos del Distrito de San Miguel - Lima y la región Cusco: 2010 - 2015 (Tesis para optar el grado de licenciado en sociología, Universidad Nacional Mayor de San Marcos, Lima, Perú).

Ku-Yanasupo, L. (2017). El control constitucional del proceso legislativo y el modelo semiprocedimental: El intento de promover parlamentos más deliberativos desde el ámbito judicial, Cuadernos sobre Jurisprudencia Constitucional, (12), pp. 257-276.

Martí, J. L. (2006). La república deliberativa. Una teoría de la democracia. Madrid: Marcial Pons.

Mendes, C. H. (2018). Cortes constitucionales y democracia deliberativa. Madrid: Marcial Pons.

Olivares, N. E. (2013). Un Enfoque Sistémico de la Democracia Deliberativa, Revista de la Facultad, IV (2), pp. 225-243.

Olivares, N. E. (2015). División deliberativa de poderes y control judicial dialógico. Cuadernos de Doctrina Judicial de la Provincia de La Pampa, VII (2), pp. 11-30

Olivares, N. E. (2017). Democracia deliberativa y control de constitucionalidad: en defensa de un sistema multisituado. Revista de derecho Universidad del Norte, (47), pp. 167-206.

Olivares, N. E. (2018). Deliberativismo republicano y control constitucional. Revista Cuestiones Constitucionales, (38), pp. 33-62.

Osei, J. (2009). The Challenge of Sustaining Emergent Democracies: Insights for Religious Intellectuals \& Leaders of Civil Society. Indiana: Xlibris Corporation.

Paredes, M. (2017). Democracia: ¿utopia o realidad? (Tesis para optar el grado de Magíster en Filosofía, Universidad Nacional Mayor de San Marcos, Lima, Perú).

Perú. Congreso Constituyente Democrático. Constitución Política del Perú, (1993).

Quiroz-Villalobos, M. (2019). Participación popular y presidencialismos fuertes en el nuevo constitucionalismo latinoamericano. Revista Derecho del Estado, Universidad Externado de Colombia, (44), pp. 99-131.

Sobrevilla, D. (1987). El programa de fundamentación de una ética discursiva de Jürgen Habermas. Ideas y Valores, 36 (74-75), pp. 99-117.

Sosa-Sacio, J. M. (2017). Los derechos sociales, su exigibilidad y el activismo judicial dialógico como ideal a seguir. En J. M. Sosa-Sacio (coord.), Igualdad, derechos sociales y control de políticas públicas en la jurisprudencia constitucional (pp.63-91). Lima: Palestra.

Rojas-Bernal, J. M. (2017). Nuestro incipiente 'activismo dialógico': las sentencias estructurales del Tribunal Constitucional. En J. M. Sosa-Sacio (coord.), Igualdad, derechos sociales y control de políticas públicas en la jurisprudencia constitucional (pp.221-256). Lima: Palestra. 
Timm, A. (2017). Activismo judicial dialógico en América Latina. La lucha por los derechos, (Tesis para optar el grado de Doctor, Universidad Carlos III de Madrid, Madrid, España).

Tribunal Constitucional del Perú (2003). Lima. Sentencia recaída en el Expediente $\mathrm{N}^{\circ}$ 014-2003-AI/TC.

Tribunal Constitucional del Perú (2011). Lima. Sentencia recaída en el Expediente $\mathrm{N}^{\circ}$ 0005-2011-PI/TC.

Tribunal Constitucional del Perú (2016). Lima. Sentencia recaída en el Expediente $N^{\circ}$ 0010-2014-PI/TC.

Tribunal Constitucional del Perú (2017). Lima. Sentencia recaída en el Expediente $\mathrm{N}^{\circ}$ 00006-2017-PI/TC.

Tribunal Constitucional del Perú (2017). Lima. Sentencia recaída en el Expediente $N^{\circ}$ 00015-2012-PI/TC.

Tribunal Constitucional del Perú (2018). Lima. Sentencia recaída en el Expediente $\mathrm{N}^{\circ}$ 0001-2018-PI/TC.

Tribunal Constitucional del Perú (2018). Lima. Sentencia recaída en el Expediente $\mathrm{N}^{\circ}$ 0006-2018-PI/TC.

Tribunal Constitucional del Perú (2018). Lima. Sentencia recaída en el Expediente $\mathrm{N}^{\circ}$ 0008-2018-PI/TC.

Tribunal Constitucional del Perú (2018). Lima. Sentencia recaída en el Expediente $\mathrm{N}^{\circ}$ 0012-2018-PI/TC y 013-2018-PUTC de 2018.

Tribunal Constitucional del Perú (2018). Lima. Sentencia recaída en el Expediente $\mathrm{N}^{\circ}$ 0017-2012-PI/TC. 